\title{
SNOW ACCUMULATION AND OXYGEN-ISOTOPE RECORDS AT THE LAW DOME SUMMIT, ANTARCTICA
}

\section{(Abstract)}

by

\section{V.I. Morgan}

(Australian Antarctic Division, Channel Highway, Kingston, Tasmania 7050, Australia)

\section{ABSTRACT}

At the summit of Law Dome $\left(66^{\circ} 44^{\prime} \mathrm{S}, 112^{\circ} 50^{\prime} \mathrm{E}\right)$ the annual snow accumulation is equivalent to $0.7 \mathrm{~m}$ of water, and seasonal cycles of oxygen-isotope ratio are preserved clearly in the firn. Isotope-ratio measurements on three $28 \mathrm{~m}$ deep ice cores taken $15 \mathrm{~m}$ apart near the summit show that although annual layer thicknesses are well correlated between the cores, the actual isotope values (even when averaged over several years' accumulation) are poorly correlated.

Since the three sites must obviously receive the same precipitation, the differences in isotope ratio imply that the amounts of the precipitation retained as accumulation from individual snow-falls throughout the year must vary. The large seasonal variation in isotope ratio then easily accounts for the offsets.

In the Law Dome region, precipitation occurs mainly as a result of cyclonic activity in spring, winter and autumn. The stronger winds experienced at these times cause the snow to be formed into large dunes, which are the stable (although moving) surface configuration under these conditions. The movement of dunes by erosion on one face and deposition on the other causes the snow in them to be well mixed. Isotope measurements on a $0.7 \mathrm{~m}$ high dune on the inland ice cap showed that it was composed of "winter" snow, with an average isotope value of $-28.2 \%$ and a range of only $1 \%$. The harder underlying snow had values which varied between -24.2 and $-27.4 \%$.

During periods of relatively calm or warm conditions the dunes become consolidated and their movement is greatly reduced. Further snow-falls then do not add accumulation to the top and up-wind side of the dunes but tend to fill them in on the down-wind side. In particular it is observed that for Law Dome the surface profile is quite rough in winter and spring, but the more gentle winds and light snow-falls experienced in summer produce a very smooth surface at the beginning of autumn, with all the surface hollows filled in.

The ice-core isotope profiles confirm the evenness of the summer accumulation, compared to that of winter. Correlation coefficients are typically 0.26 for the winter minima and 0.65 for the summer peak in isotope ratio. This means that somewhat shorter averaging times can be used when compiling "climatic" records from isotope profiles if only the "summer" isotope values are used. This is useful in comparison of isotopic and meteorological data when only a limited time span is available.

Apart from the short-term effects, which can be reduced as desired by longer averaging periods, these core studies also demonstrate how any process which can modulate the precipitation or accumulation will also affect the isotopic composition of the accumulated snow. 